Steel $\mathrm{DH}$, Joussen AM, Wong D. ILM peeling in rhegmatogenous retinal detachment; does it improve the outcome? Graefe's Archive for Clinical and Experimental Ophthalmology 2018, 256, 247-248.

DOI link

https://doi.org/10.1007/s00417-017-3876-6

ePrints link

http://eprint.ncl.ac.uk/246489

Date deposited

$01 / 03 / 2018$

Embargo release date

$27 / 12 / 2018$

Copyright

The final publication is available at Springer via https://doi.org/10.1007/s00417-017-3876-6 


\section{Graefe's Archive for Clinical and Experimental Ophthalmology ILM peeling in rhegmatogenous retinal detachment; Does it improve the outcome? --Manuscript Draft--}

Manuscript Number:

Full Title:

Article Type:

Keywords:

\begin{tabular}{|l}
\hline Corresponding Author: \\
\hline $\begin{array}{l}\text { Corresponding Author Secondary } \\
\text { Information: }\end{array}$ \\
\hline
\end{tabular}

Corresponding Author's Institution:

Corresponding Author's Secondary Institution:

First Author:

First Author Secondary Information:

Order of Authors:

\begin{tabular}{|l|l|}
\hline & Antonia M Joussen \\
\hline David Wong \\
\hline
\end{tabular}

Order of Authors Secondary Information:

Funding Information:

Retinal detachment

ILM peeling

Silicone oil

David H W Steel

David H W Steel

David H W Steel

David Wong
ILM peeling in rhegmatogenous retinal detachment; Does it improve the outcome?

Editorial (by Invitation)

Internal limiting membrane

Sunderland Eye Infirmary

Sunderland, Tyne and Wear UNITED KINGDOM

Sunderland Eye Infirmary 


\title{
ILM peeling in rhegmatogenous retinal detachment; Does it improve the outcome?
}

\author{
Steel DH ${ }^{1,2}$ \\ Joussen $\mathrm{AM}^{3}$ \\ Wong $D^{4}$
}

1 Sunderland Eye Infirmary, Queen Alexandra Road, Sunderland, UK

2 Institute of Genetic Medicine, Newcastle University, Newcastle Upon Tyne, UK

3 Department of Ophthalmology, Charité Universitätsmedizin, Berlin

4 St. Paul's Eye Unit, Royal Liverpool University Hospital Trust, Liverpool, UK.

Correspondence to:

Mr D Steel

Sunderland Eye Infirmary

Queen Alexandra Road

Sunderland

UK

David.steel@ncl.ac.uk

Telephone: +44(0)1915699065

Fax: +44(0) 1915699060 
Peeling of the internal limiting membrane at the macula has been shown to improve visual outcomes in a number of diseases most notably large macular holes. Perhaps partly related to it being a surgically satisfying manoeuvre, its use has been extended to a wide variety of vitreoretinal indications including more recently and controversially primary rhegmatogenous detachment. Previous studies have suggested that its use reduces postoperative ERM formation and may improve visual results, although these have largely been retrospective or small comparative but non randomised studies [1-5]. In this issue however Eissa et al. report a randomised controlled study of ILM peeling in 43 eyes undergoing vitrectomy for macula involving retinal detachment and report a detrimental effect of ILM peeling [6]. Although there was a lower incidence of ERM in the ILM peel group, visual acuity and macular sensitivity were significantly better in the no peel group. The studies generalisability can be criticised in that silicone oil was used in all eyes despite all cases having less than C PVR based on lack of access to long acting gases. There was also a significantly longer duration of macula detachment in the peel group, and a significantly greater extent of retinal detachment in the non peel group, however neither of these differences were significant to final visual outcome on multivariate analysis.

Being the only randomised study to date on this subject the findings of Eissa et al deserve to be taken seriously. There are a number of possible explanations for the apparent detrimental effect of ILM peeling in this series.

ILM peeling is known to have a number of potentially adverse effects on retinal structural and function no matter how carefully performed, related to that fact that when the ILM is peeled from the retinal surface fragments of the underlying Muller cell end feet are avulsed with it [7]. Interestingly the extent to which this occurs varies by disease, and a deeper plane of separation may have greater effects on retinal function. ILM examined from patients undergoing idiopathic ERM peeling have shown more Muller cell fragments, suggestive of a deeper plane of separation, than in those from macular hole specimens without ERM [8]. It is well known that in retinal detachment, Muller cell activation and elongation of their processes occurs not only towards the outer retina but also to, and through the internal limiting membrane onto the retinal surface with ERM formation [9]. Forced avulsion of the ILM by peeling from the retinal surface in this situation would thus likely have a more profound effect on retinal structure and function than in a non-activated state. The extent of Muller cell activation is at least in part related to RRD duration and it is significant that Eissa et al observed a very marked dimpling of the retinal surface representing a severe 'dissociated optic nerve fibre layer appearance' (DONFL) in the ILM peeled group. Relevantly DONFL severity has been related to the amount of Muller cell material avulsed during ILM peeling, and possibly to visual outcome in macular hole surgery [10]. It is also possible that ILM peeling in a detached retina is more traumatic per se than in attached retina related to surgical difficulty and variable angle of peel in a mobile retina [5]. Eissa et al used BBG with a contact time of 30 seconds to stain the ILM and peeled without the use of heavy liquids to stabilise the retina as other authors have described [11].

Silicone oil was used in all cases in the RCT and oil related visual loss may have played a role in the outcomes. Although the pathogenesis of this enigmatic condition is unclear it has 
been consistently linked to changes in the inner retina [12-14]. ILM peeling would clearly increase oil/nerve fibre layer contact and the potential for a toxic effect The incidence of oil related visual loss has also been recently linked with raised intraocular pressure although pressure changes were not reported in the study [15].

The main benefit proposed for ILM peeling in RRD surgery has been a reduction of postoperative ERM with several studies reporting large differences [1-4], with high prevalence in the non peeling groups. The incidence of ERM reported after retinal detachment varies widely depending on the definition used and case mix of the RRDs but ERM thought to have a significant visual effect has typically been reported in $\sim 4-8 \%$ of cases of uncomplicated RRD (i.e. without pre-existing PVR) treated with vitrectomy surgery $[16,17]$. Eissa et al observed that although there was a difference in the prevalence of ERM on postoperative OCTs in their study, none of the ERMs seen in the no peel group were clinically significant and non-required further surgery. The clear question that arises is whether the potential morbidity of ILM peeling is warranted in uncomplicated RRD when the incidence of significant ERM is so low. Indeed, ERM can be peeled post RRD repair if required with good results (even without ILM peeling) [18].

ILM peeling in RRD can only be justified if it improves results. This RCT, albeit small and single surgeon suggests that it doesn't in macula involving RRD without PVR tamponaded with silicone oil. Indeed, it had a deleterious effect on outcome. It may be it has a role in subsets of patients e.g. those with PVR and those with macular on or just off cases. Further well designed RCTs in macula attached and detached cases will be needed to answer this controversy definitively, but in the meantime we would suggest that it should not be regarded as standard practice.

References

1) Forlini $M$, Date $P$, Ferrari LM et al. COMPARATIVE ANALYSIS OF RETINAL REATTACHMENT SURGERY WITH OR WITHOUT INTERNAL LIMITING MEMBRANE PEELING TO PREVENT POSTOPERATIVE MACULAR PUCKER. Retina. 2017 Jul 18.

2) Akiyama K, Fujinami K, Watanabe K, Tsunoda K, Noda T. Internal Limiting Membrane Peeling to Prevent Post-vitrectomy Epiretinal Membrane Development in Retinal Detachment. Am J Ophthalmol. 2016;171:1-10.

3) Aras C, Arici C, Akar S et al. (2009) Peeling of internal limiting membrane during vitrectomy for complicated retinal detachment prevents epimacular membrane formation. Graefes Arch Clin Exp Ophthalmol; 247(5): 619-23

4) Nam KY, Kim JY. Effect of internal limiting membrane peeling on the development of epiretinal membrane after pars plana vitrectomy for primary rhegmatogenous retinal detachment. Retina. 2015;35:880-5. 
5) Hisatomi T, Tachibana T, Notomi S et al. INTERNAL LIMITING MEMBRANE PEELINGDEPENDENT RETINAL STRUCTURAL CHANGES AFTER VITRECTOMY IN RHEGMATOGENOUS RETINAL DETACHMENT. Retina. 2017 Feb 23.

6) Eissa et al. Functional and Structural Outcomes of ILM Peeling in Uncomplicated Macula Off RRD Using Microperimetry \& En-Face OCT. Graefes Arch Clin Exp Ophthalmol.

7) Chatziralli IP, Theodossiadis PG, Steel DHW. INTERNAL LIMITING MEMBRANE PEELING IN MACULAR HOLE SURGERY; WHY, WHEN, AND HOW? Retina. 2017 Nov 23.

8) Kenawy N, Wong D, Stappler T et al. Does the presence of an epiretinal membrane alter the cleavage plane during internal limiting membrane peeling? Ophthalmology. 2010;117:320-3

9) Sethi CS, Lewis GP, Fisher SK et al. Glial remodeling and neural plasticity in human retinal detachment with proliferative vitreoretinopathy. Invest Ophthalmol Vis Sci. 2005;46:329-42.

10) Steel DH, Dinah C, White K, Avery PJ. The relationship between a dissociated optic nerve fibre layer appearance after macular hole surgery and Muller cell debris on peeled internal limiting membrane. Acta Ophthalmol. 2017;95:153-157.

11) Höhn F, Kretz FT, Pavlidis M. [Primary vitrectomy with peeling of the internal limiting membrane under decaline: a promising surgical maneuver for treatment of total and subtotal retinal detachment]. Ophthalmologe. 2014;111:882-6.

12) Purtskhvanidze K, Hillenkamp J, Tode J et al. Thinning of Inner Retinal Layers after Vitrectomy with Silicone Oil versus Gas Endotamponade in Eyes with Macula-Off Retinal Detachment. Ophthalmologica. 2017;238:124-132.

13) Christensen UC, la Cour M. Visual loss after use of intraocular silicone oil associated with thinning of inner retinal layers. Acta Ophthalmol. 2012;90:733-7.

14) Caramoy A, Droege KM, Kirchhof B, Fauser S. Retinal layers measurements in healthy eyes and in eyes receiving silicone oil-based endotamponade. Acta Ophthalmol. 2014;92:292-7.

15) Marti M, Walton R, Böni C, Zweifel SA, Stahel M, Barthelmes D. INCREASED INTRAOCULAR PRESSURE IS A RISK FACTOR FOR UNEXPLAINED VISUAL LOSS DURING SILICONE OIL ENDOTAMPONADE. Retina. 2017 Jan 16.

16) Martínez-Castillo V, Boixadera A, Distéfano L, Zapata M, García-Arumí J. Epiretinal membrane after pars plana vitrectomy for primary pseudophakic or aphakic rhegmatogenous retinal detachment: incidence and outcomes. Retina. 2012;32:1350-5. 
17) Heo MS, Kim HW, Lee JE, Lee SJ, Yun IH. The clinical features of macular pucker formation after pars plana vitrectomy for primary rhegmatogenous retinal detachment repair. Korean J Ophthalmol. 2012;26:355-61.

18) Council MD, Shah GK, Lee HC, Sharma S. Visual outcomes and complications of epiretinal membrane removal secondary to rhegmatogenous retinal detachment. Ophthalmology. 2005;112:1218-21. 